\author{
А. Н. Шиманская ${ }^{1}$, Р. Ю. Попов ${ }^{1}$, Ф. И. Пантелеенко ${ }^{2}$, А. Д. Подсосонная ${ }^{1}$, \\ Д. А. Байгазин ${ }^{1}$, А. В. Поспелов ${ }^{1}$ \\ ${ }^{1}$ Белорусский государственный технологический университет \\ ${ }^{2}$ Белорусский национальный технический университет
}

\title{
РАЗРАБОТКА СОСТАВОВ МАСС НА ОСНОВЕ ФОСФАТОВ КАЛЬЦИЯ ДЛЯ 3D-ПЕЧАТИ КЕРАМИЧЕСКИХ ИЗДЕЛИЙ
}

Создание персонализированных конструкций для тканевой инженерии костной ткани на основе фосфатов кальция методами трехмерной печати является одним из перспективных направлений развития аддитивных технологий. В настоящей работе проведено комплексное изучение влияния параметров жидкофазного синтеза гидроксиапатита ( $\mathrm{pH}$ реакционной среды, температура, продолжительность выдержки осадка в маточном растворе, обработка маточного раствора с осадком электромагнитным излучением СВЧ-диапазона) на фазовый и гранулометрический состав полученного порошка, особенности его структуры*. В результате этого выбраны оптимальные условия синтеза гидроксиапатита: $\mathrm{pH} 10$, температура $60^{\circ} \mathrm{C}$, обработка маточного раствора электромагнитным излучением СВЧ-диапазона мощностью 700 Вт в течение 30 мин. Для формования изделий разработана конструкция 3D-принтера, собрана экспериментальная установка. Определены технологические свойства керамических масс, пригодных для 3D-печати: динамическая вязкость - $20000-60000$ мПа·с; pH 7-8; влажность - 54-60 мас. \%, а при использовании связующих добавок - 70 мас. \%. С помощью дифференциальной сканирующей калориметрии определены температурно-временные параметры обжига изделий, полученных на основе синтезированного гидроксиапатита. Выявлена взаимосвязь между составом керамических масс, технологическими параметрами получения, особенностями структуры и физико-химическими свойствами кальцийфосфатных материалов.

Ключевые слова: жидкофазный синтез, гидроксиапатит, 3D-печать, динамическая вязкость, структура.

Для цитирования: Шиманская А. Н., Попов Р. Ю., Пантелеенко Ф. И., Подсосонная А. Д., Байгазин Д. А., Поспелов А. В. Разработка составов масс на основе фосфатов кальция для 3D-печати керамических изделий // Труды БГТУ. Сер. 2, Химические технологии, биотехнологии, геоэкология. 2021. № 2 (247). С. 187-198.

\section{H. M. Shymanskaya ${ }^{1}$, R. Yu. Popov ${ }^{1}$, F. I. Pantsialeyenka ${ }^{2}$, A. D. Podsosonnaya ${ }^{1}$, D. A. Baihazin ${ }^{1}$, A. V. Pospelov ${ }^{1}$ \\ ${ }^{1}$ Belarusian State Technological University \\ ${ }^{2}$ Belarusian National Technical University}

\section{DEVELOPMENT OF CALCIUM PHOSPHATE COMPOSITIONS FOR 3D PRINTING OF CERAMICS}

Creation of personalized structures for bone tissue engineering based on calcium phosphates using 3D printing methods is one of the promising directions in the development of additive technologies. In this work, a comprehensive study of the influence of the liquid-phase synthesis parameters of hydroxyapatite $(\mathrm{pH}$ of the reaction medium, temperature, the duration of holding the precipitate in the mother liquor, subjecting of the mother liquor with the precipitate to microwave irradiation) on the phase composition and particle size distribution of the obtained powder, features of it structure have been carried out. As a result, the optimal conditions have been chosen for the synthesis of hydroxyapatite: $\mathrm{pH} 10$, temperature $60^{\circ} \mathrm{C}$, subjecting of the mother liquor with the precipitate to microwave irradiation ( $700 \mathrm{~W}$, $30 \mathrm{~min}$ ). For the molding of ceramics the design of a 3D printer have been developed and the experimental $3 \mathrm{D}$ printer have been assembled. The technological properties of ceramic masses suitable for $3 \mathrm{D}$ printing have been determined: dynamic viscosity - 20,000-60,000 $\mathrm{mPa} \cdot \mathrm{s}$; $\mathrm{pH} 7-8$; moisture content -54 $60 \mathrm{wt} . \%$, and when using binding additives $-70 \mathrm{wt} . \%$. Using differential scanning calorimetry, the temperature-time firing parameters of ceramics on the base of synthesized hydroxyapatite have been determined. The relationship between the composition of ceramics, technological parameters of production, structural features and physico-chemical properties of calcium phosphate materials has been revealed.

\footnotetext{
*Исследования выполнены в рамках проекта Белорусского республиканского фонда фундаментальных исследований (грант БРФФИ № Т20М-034).
} 
Key words: liquid-phase synthesis, hydroxyapatite, 3D printing, dynamic viscosity, structure.

For citation: Shymanskaya H. M., Popov R. Yu., Pantsialeyenka F. I., Podsosonnaya A. D., Baihazin D. A., Pospelov A. V. Development of calcium phosphate compositions for 3D printing of ceramics. Proceedings of BSTU, issue 2, Chemical Engineering, Biotechnologies, Geoecology, 2021, no. 2 (247), pp. 187-198 (In Russian).

Введение. В последние годы значительное внимание уделяется созданию керамических материалов медицинского назначения, предназначенных для реконструкции дефектов костных тканей, образующихся в результате патологических изменений в организме, обширных хирургических вмешательств или травм. Применение для этих целей материалов на основе фосфатов кальция, характеризующихся биологической совместимостью с тканями организма и активностью по отношению к соединению с костной тканью и формированию новой костной ткани, предоставляет уникальные возможности в этом направлении [1].

Использование 3D-печати для получения керамических биоматериалов позволит получать имплантаты индивидуально для каждого пациента, а также существенно сократить сроки их изготовления.

Изучением возможности применения аддитивных технологий для создания керамических материалов на основе фосфатов кальция занимаются крупнейшие научно-технические центры по всему миру. Наиболее известными методами 3D-печати являются следующие [2]: стереолитография (SLA), Multi-Jet Modeling (MJM), Robocasting, селективное лазерное спекание (SLS), селективное лазерное плавление (SLM), лазерно-сетчатое проецирование (LENS), трехмерная печать (3DP), технология NanoParticle Jetting (NPJ), двухфотонная полимеризация (TPP) и др. При получении керамических изделий широко используемым процессом 3D-печати является экструзия. Поскольку керамические порошки, состоящие из высокодисперсных частиц, как правило, являются низкотекучими, обладают низкой пластичностью, для формования изделий в составы масс необходимо вводить связующие добавки.

Цель настоящей работы заключается в разработке составов и технологических параметров получения пористых керамических изделий на основе фосфатов кальция с помощью аддитивных технологий.

Кристаллический гидроксиапатит получают чаще всего методами жидкофазного или твердофазного синтеза. Последние проводятся при высоких температурах, что ведет к росту размеров частиц, снижению удельной поверхности порошков и, следовательно, делает их малопригодными для получения имплантатов. Кроме того, продуктам твердофазного синтеза свойственны химическая и минералогическая неоднородность, а также химическая инертность [3-4]. Напротив, продукты жидкофазного синтеза отличаются химической однородностью. Их дисперсность определяется концентрацией прекурсоров; меньшая концентрация обусловливает получение высокодисперсных порошков.

Поскольку при жидкофазном синтезе могут образовываться промежуточные и сопутствующие фазы, которые в дальнейшем оказывают негативное воздействие на окружающие имплантат ткани при реконструкции и замещении участков костной ткани, достаточно часто для синтеза гидроксиапатита используется взаимодействие гидроксида кальция и фосфорной кислоты, при котором единственным продуктом реакции помимо основного продукта является вода [5-10]. Однако наиболее распространенной реакцией служит взаимодействие нитрата кальция и гидрофосфата аммония, при котором образуется легко удаляемый летучий аммиак [11-15]. Образующийся нитрат аммония перитектически разлагается при температуре около $210^{\circ} \mathrm{C}$ на газообразные $\mathrm{N}_{2} \mathrm{O}$ и $\mathrm{H}_{2} \mathrm{O}$. Также для синтеза порошков фосфатов кальция (гидроксиапатита), свободных от цитотоксичных неорганических примесей, могут применяться следующие реакции взаимодействия: нитрита кальция и фосфата аммония [16]; ацетата кальция $\mathrm{Ca}\left(\mathrm{CH}_{3} \mathrm{COO}\right)_{2}$ и триэтилфосфата $\left(\mathrm{C}_{2} \mathrm{H}_{5} \mathrm{O}\right)_{3} \mathrm{PO}_{4}[17]$; сахарата кальция и гидрофосфата аммония [18]; ацетата кальция $\mathrm{Ca}\left(\mathrm{CH}_{3} \mathrm{COO}\right)_{2}$ и гидрофосфата аммония $\left(\mathrm{NH}_{4}\right)_{2} \mathrm{HPO}_{4}[19]$; лактата кальция и гидрофосфата аммония [20].

Необходимо отметить, что проведение остаривания (выдерживания осадка в маточном растворе) в течение длительного времени, термообработка при высокой температуре приводит к формированию крупнокристаллического порошка. Напротив, повышение концентрации исходных растворов; уменьшение времени пребывания осадка в маточном растворе; использование поверхностно-активных веществ, высокомолекулярных соединений (поливиниловый спирт, карбоксиметилцеллюлоза) или крупных органических анионов (например, $\mathrm{CH}_{3} \mathrm{COO}^{-}$), которые, адсорбируясь на поверхности вновь образованных частиц, могут блокировать их дальнейший рост, способствуют снижению размеров формирующихся частиц и повышению активности порошков к спеканию [15, 21-26]. 
Использование электромагнитного излучения СВЧ-диапазона, ультразвуковой обработки, механохимической активации и других способов воздействия на реакционные растворы позволяет синтезировать наноразмерные частицы фосфатов кальция [27-30].

Ввиду вышесказанного в настоящей работе для синтеза фосфатов кальция (гидроксиапатита) целесообразно использовать метод жидкофазного синтеза. Для управления фазовым составом и степенью кристалличности синтезируемых порошков будет применяться обработка маточного раствора с осадком электромагнитным излучением СВЧ-диапазона.

Основная часть. Синтез гидроксиапатита проводился методом осаждения из водных растворов по следующей реакции:

$$
\begin{aligned}
& 6\left(\mathrm{NH}_{4}\right)_{2} \mathrm{HPO}_{4}+10 \mathrm{Ca}\left(\mathrm{NO}_{3}\right)_{2}+8 \mathrm{NH}_{4} \mathrm{OH} \rightarrow \\
& \rightarrow \mathrm{Ca}_{10}\left(\mathrm{PO}_{4}\right)_{6}(\mathrm{OH})_{2}+20 \mathrm{NH}_{4} \mathrm{NO}_{3}+6 \mathrm{H}_{2} \mathrm{O} \text {. }
\end{aligned}
$$

В качестве исходных компонентов использовались следующие: тетрагидрат нитрата кальция $\mathrm{Ca}\left(\left(\mathrm{NO}_{3}\right)_{2}\right) \cdot 4 \mathrm{H}_{2} \mathrm{O}$ (х. ч., ГОСТ 4142); гидроортофосфат аммония $\left(\mathrm{NH}_{4}\right)_{2} \mathrm{HPO}_{4}$ марки А (ГОСТ 8515); 25\%-ный водный раствор аммиака $\mathrm{NH}_{4} \mathrm{OH}$ (ос. ч., ГОСТ 24147).

В химический стакан объемом 500 мл с мешалкой помещался $0,1 \mathrm{M}$ водный раствор нитрата кальция и нагревался до температуры 40 или $60^{\circ} \mathrm{C}$, после чего в него с помощью бюретки добавлялся 0,1 М раствор гидроортофосфата аммония по каплям. $\mathrm{NH}_{4} \mathrm{OH}$ вводился для поддержания $\mathrm{pH}$ раствора на необходимом уровне (7-12). Значение $\mathrm{pH}$ контролировалось электронным pH-метром HI 8314 HANNA Instruments (Германия). Полученный в результате синтеза маточный раствор с осадком подвергался воздействию электромагнитного излучения СВЧдиапазона мощностью 700 Вт в течение 30 мин либо выдерживался 1, 3 сут, затем отфильтровывался и промывался на фильтре до нейтрального значения $\mathrm{pH}$, сушился при $80^{\circ} \mathrm{C}$ в сушильном шкафу SNOL 58/350 (Литва).

C помощью рентгенофазового анализа (дифрактометры «ДРОН-2» (Россия) и Panalytical Empyrean DY1098 (Англия)) установлено, что независимо от $\mathrm{pH}$ реакционной среды и температуры синтеза при обработке маточного раствора с осадком электромагнитным излучением СВЧ-диапазона формируется гидроксиапатит с низкой степенью кристалличности. Об этом свидетельствует невысокое разрешение линий спектра гидроксиапатита на дифрактограмме (рис. $1, a)$, а также результаты энергодисперсионной рентгеновской спектроскопии. Так, например, при $\mathrm{pH} 12$ и температуре синтеза $40^{\circ} \mathrm{C}$ соотношение кальция и фосфора варьируется в интервале 1,79-2,02 (рис. 2).
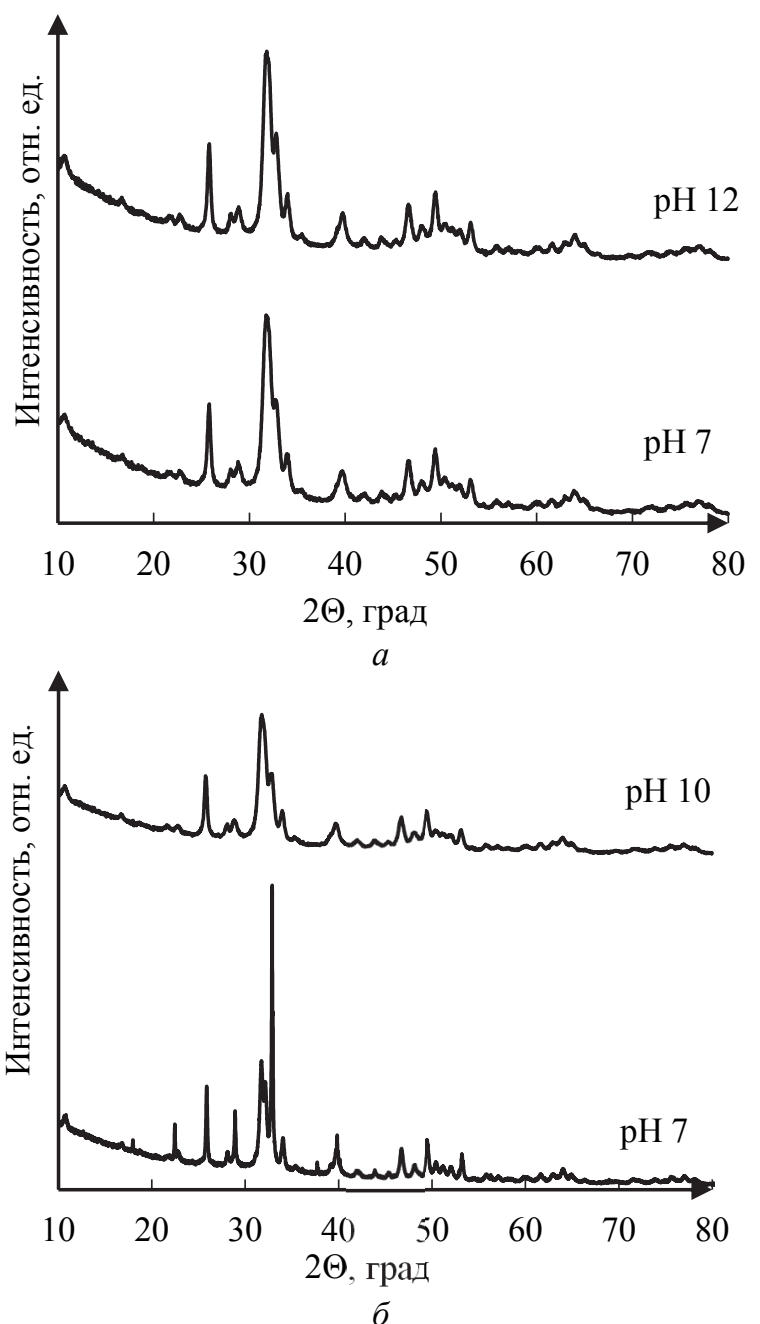

Рис. 1. Дифрактограммы порошков, синтезированных: $a-$ при рН 7 и $12,60^{\circ} \mathrm{C}$ и обработке маточного раствора электромагнитным излучением

СВЧ-диапазона в течение 30 мин; $\sigma$ - при рН 7 и 10, $60^{\circ} \mathrm{C}$ и выдержке осадка в маточном растворе 3 сут

Как известно [26], стехиометрическое соотношение $\mathrm{Ca} / \mathrm{P}$ в гидроксиапатите составляет 1,67. Отклонение соотношения $\mathrm{Ca} / \mathrm{P}$ от стехиометрического также подтверждает образование аморфного фосфата кальция.

Формирование гидроксиапатита с низкой степенью кристалличности наблюдалось при $\mathrm{pH}$ 10-12 независимо от продолжительности выдержки в маточном растворе (рис. $1, \sigma)$.

Следует отметить, что повышению степени кристалличности продукта синтеза способствует снижение $\mathrm{pH}$ реакционной среды до 7 (рис. 1, б), а также повышение температуры до $60^{\circ} \mathrm{C}$ (рис. 3).

Более полная информация о влиянии $\mathrm{pH}$ реакционной смеси на структуру порошков, синтезированных при температуре $60^{\circ} \mathrm{C}$, получена с использованием инфракрасной спектроскопии (ИК-Фурье спектрометр NEXUS E.S.P. (Thermo Scientific, США)). 


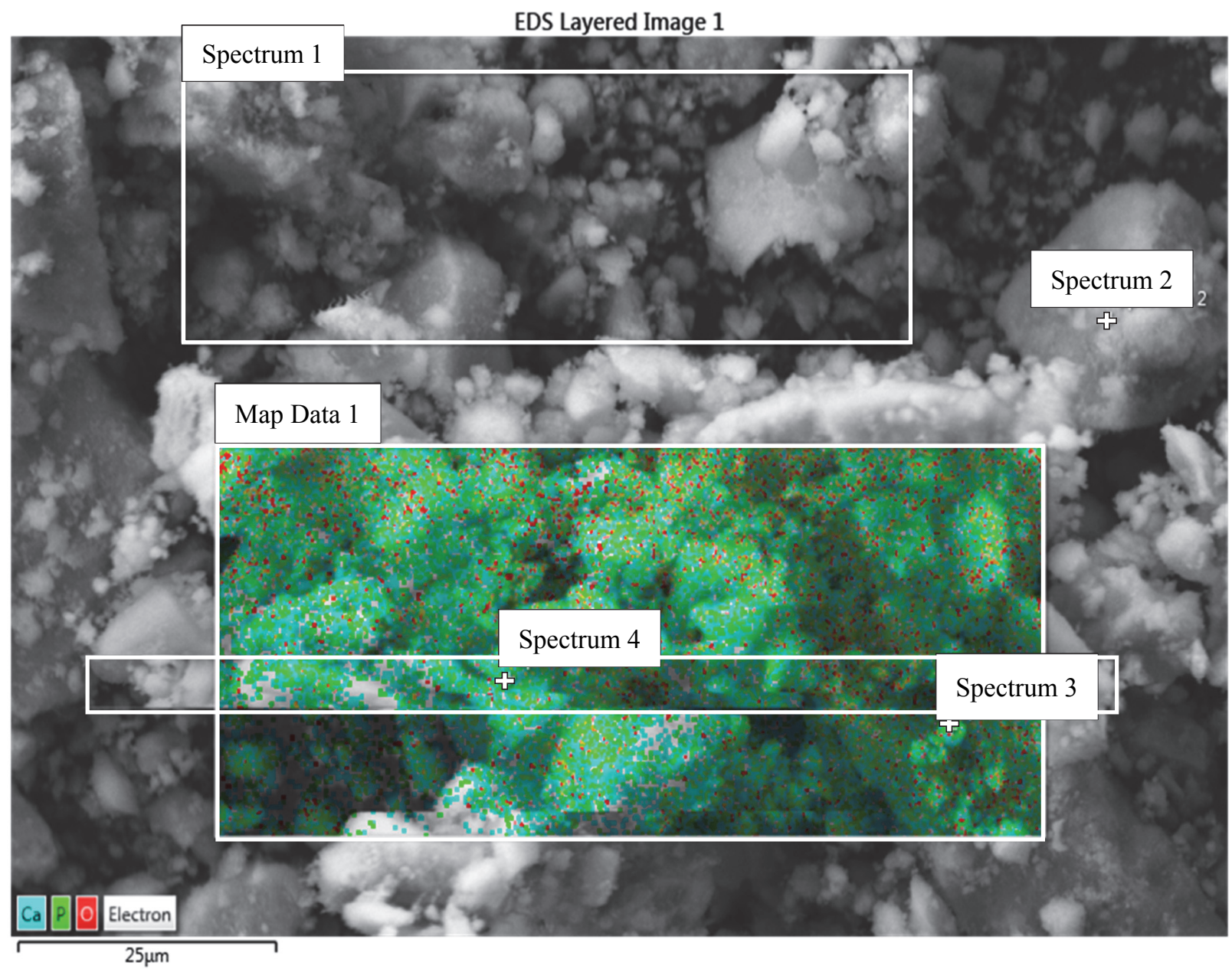

\begin{tabular}{|c|c|c|c|c|c|}
\hline \multirow{2}{*}{ Элемент } & \multicolumn{5}{|c|}{ Содержание, мас. \% } \\
\cline { 2 - 6 } & Map Sum Spectrum & Spectrum 1 & Spectrum 2 & Spectrum 3 & Spectrum 4 \\
\hline $\mathrm{Ca}$ & 39,80 & 33,21 & 41,56 & 32,91 & 56,41 \\
\hline $\mathrm{P}$ & 15,20 & 13,83 & 16,74 & 14,22 & 21,36 \\
\hline $\mathrm{O}$ & 40,40 & 45,66 & 35,35 & 44,39 & 18,57 \\
\hline $\mathrm{C}$ & 4,60 & 7,30 & 6,35 & 8,48 & 3,66 \\
\hline
\end{tabular}

Рис. 2. Результаты энергодисперсионной рентгеновской спектроскопии гидроксиапатита, синтезированного при $\mathrm{pH} 12,40^{\circ} \mathrm{C}$ и выдержке осадка в маточном растворе 3 сут
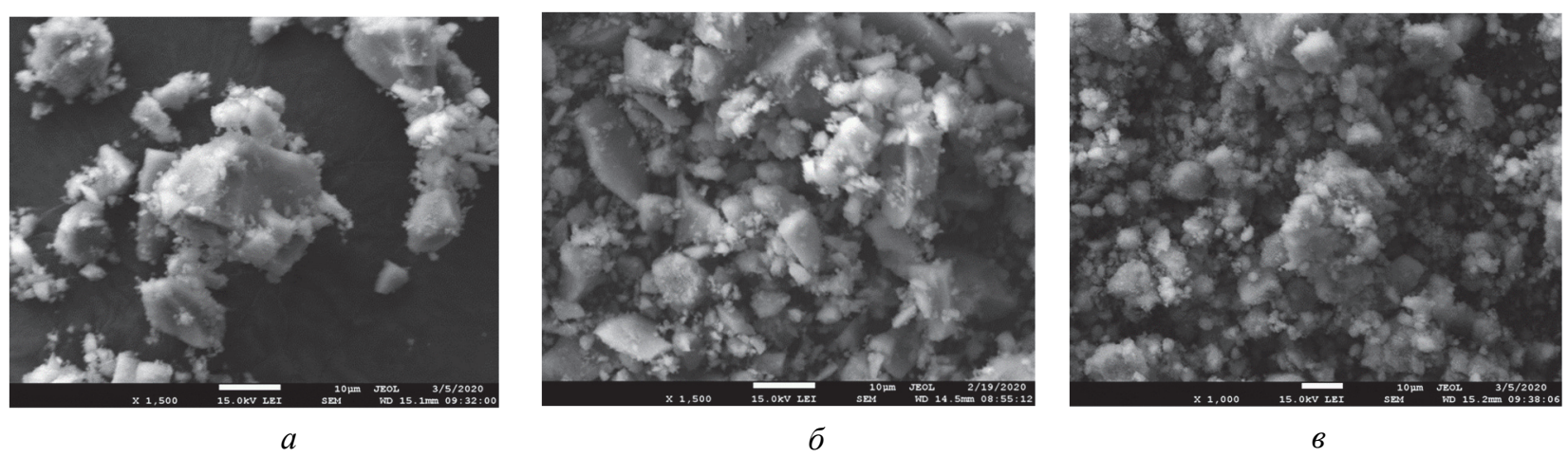

Рис. 3. Микроструктура гидроксиапатита, полученного при различных условиях: $a-\mathrm{pH} 10,20^{\circ} \mathrm{C}$, выдержка осадка 3 сут; $\sigma-\mathrm{pH} 10,40^{\circ} \mathrm{C}$, выдержка осадка 3 сут; $8-\mathrm{pH} 10,60^{\circ} \mathrm{C}$, выдержка осадка 3 сут (JEOL JSM-7600 F/EDS/WDS/EBSD) 
Как видно из рис. 4, на ИК-спектрах независимо от $\mathrm{pH}$ присутствуют полосы поглощения при 471-473 см - дважды вырожденные деформационные колебания $\mathrm{v}_{2} \mathrm{O}-\mathrm{P}-\mathrm{O}$ в $\mathrm{PO}_{4}{ }^{3-} ; 564$

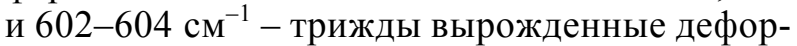
мационные колебания $v_{4} \mathrm{O}-\mathrm{P}-\mathrm{O} \quad$ в $\mathrm{PO}_{4}{ }^{3-}$; $962 \mathrm{~cm}^{-1}$ - полносимметричные колебания $\mathrm{P}-\mathrm{O}$ в $\mathrm{PO}_{4}{ }^{3-} ; 1623-1631 \mathrm{~cm}^{-1}$ - деформационные колебания Н-O-Н в адсорбированной воде; 34013410 и 3571-3572 см${ }^{-1}$ - валентные колебания $\mathrm{OH}^{-}$в адсорбированной воде [31].

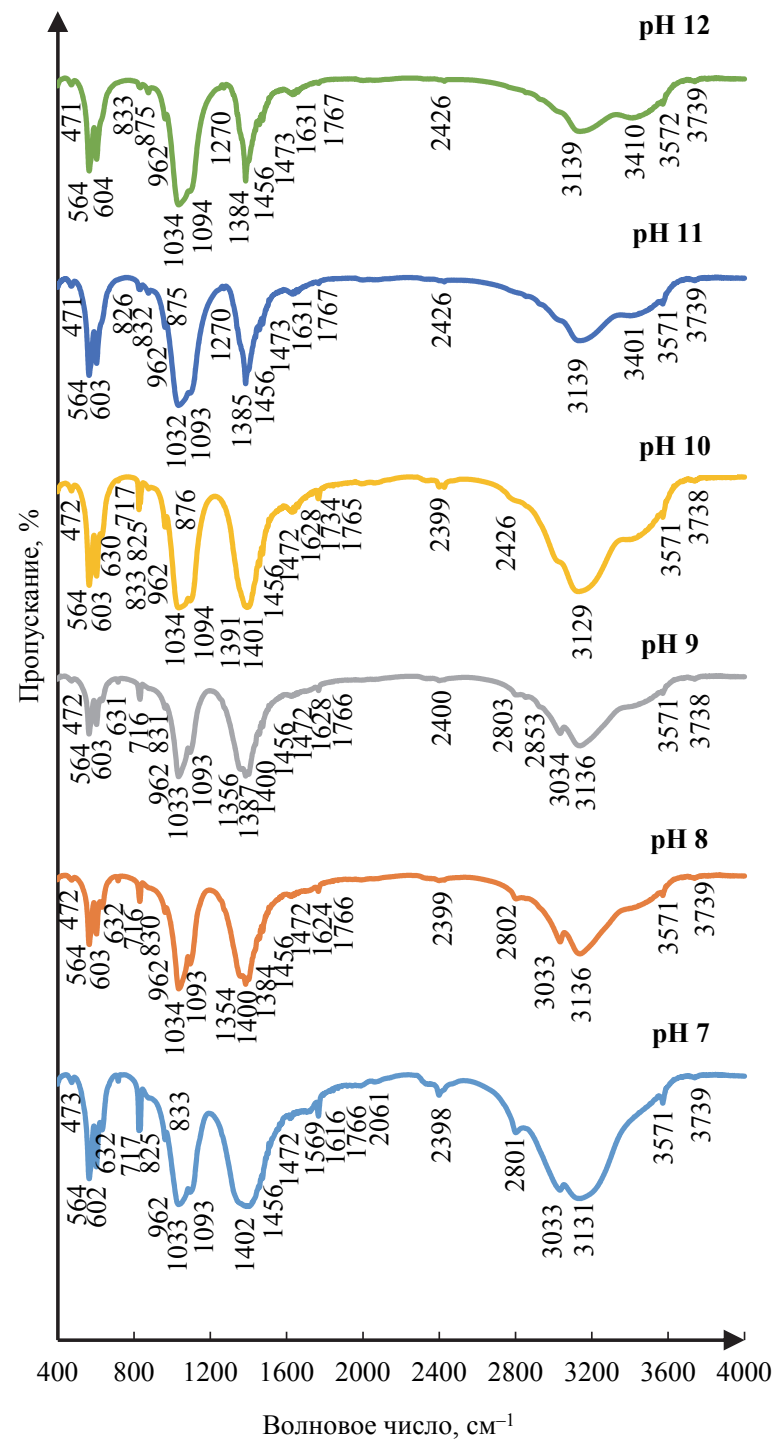

Рис. 4. ИК-спектры синтезированных порошков

Рефлексы при 1032-1034 и 1093-1094 см ${ }^{-1}$ вызваны антисимметричными валентными колебаниями связей $\mathrm{P}-\mathrm{O}, v_{3}$ [32].

В структуре гидроксиапатита обнаружено замещение $\mathrm{OH}^{-}$и $\mathrm{PO}_{4}{ }^{3-}$ на $\mathrm{CO}_{3}{ }^{2-}$ (A- и В-тип изоморфизма), что подтверждается наличием полос при 1472-1473 $\mathrm{cm}^{-1}$ - ассимметричные валентные колебания $\mathrm{C}-\mathrm{O}$ в $\mathrm{CO}_{3}{ }^{2-} \rightarrow \mathrm{PO}_{4}^{3-} ; 1456 \mathrm{~cm}^{-1}-$ ассимметричные валентные колебания $\mathrm{C}-\mathrm{O}$ в
$\mathrm{CO}_{3}{ }^{2-} \rightarrow \mathrm{OH}^{-} ; 875-876 \mathrm{~cm}^{-1}$ - деформационные колебания $\mathrm{O}-\mathrm{C}-\mathrm{O}$ в $\mathrm{CO}_{3}{ }^{2-} \rightarrow \mathrm{PO}_{4}{ }^{3-}$. Наличие карбонатных групп связано, вероятно, с адсорбцией углекислого газа из атмосферы воздуха в процессе синтеза. Необходимо отметить, что присутствие карбонат-иона является особенностью биологического гидроксиапатита, составляющего костные ткани организма [31].

На ИК-спектрах порошков, полученных при pH 7-10, присутствует полоса пропускания 716$717 \mathrm{~cm}^{-1}$, характерная для колебаний $\mathrm{CO}_{3}{ }^{2-}$ в карбонате кальция. Следовательно, в синтезированных при рН 7-10 продуктах может содержаться примесь $\mathrm{CaCO}_{3}$, количество которой уменьшается с повышением $\mathrm{pH}$.

Наблюдаемое снижение интенсивности максимума при 630-632 $\mathrm{cm}^{-1}$ с ростом $\mathrm{pH}$ вплоть до исчезновения при $\mathrm{pH} 11-12$, вероятно, указывает на образование в результате синтеза нестехиометрической аморфной фазы фосфата кальция [33].

Кроме того, инфракрасная спектроскопия показала присутствие примесных гидроксида и нитрата аммония.

С помощью сравнительного гранулометрического анализа порошков, полученных при $\mathrm{pH} 10$ и температуре $60^{\circ} \mathrm{C}$, выявлено, что количество частиц размером 0,5-10 мкм при выдержке осадка в маточном растворе 1 сут составляло 21,87 мас. $\%$, при 3 сут - 23,24 мас. \%, применение электромагнитного излучения СВЧ-диапазона способствовало увеличению доли частиц размером $0,05-$ 10 мкм до 45,80 мас. \%, при этом фракция 50200 мкм отсутствовала (рис. 5-7).

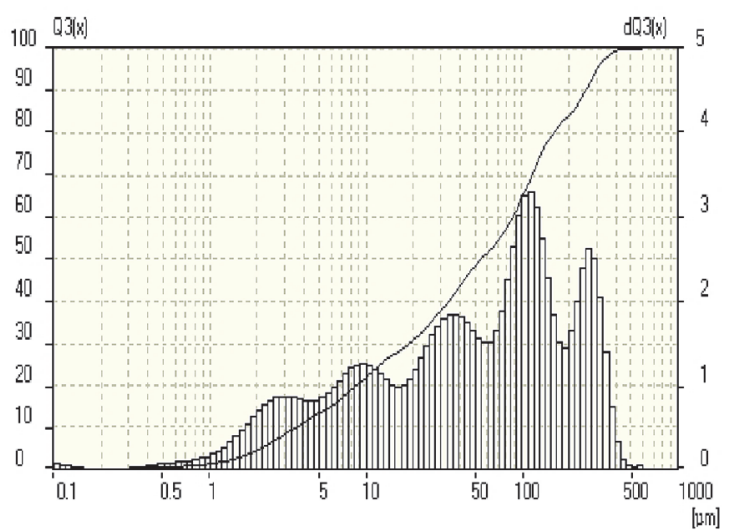

Рис. 5. Дифференциальная и интегральная кривые распределения частиц по размерам порошка, полученного при $\mathrm{pH} 10,60^{\circ} \mathrm{C}$ и выдержке осадка в маточном растворе 1 сут

Таким образом, в качестве оптимальных условий синтеза гидроксиапатита выбраны следующие: $\mathrm{pH} 10$, температура $60^{\circ} \mathrm{C}$, обработка маточного раствора с осадком электромагнитным излучением СВЧ-диапазона мощностью 700 Вт в течение 30 мин. 


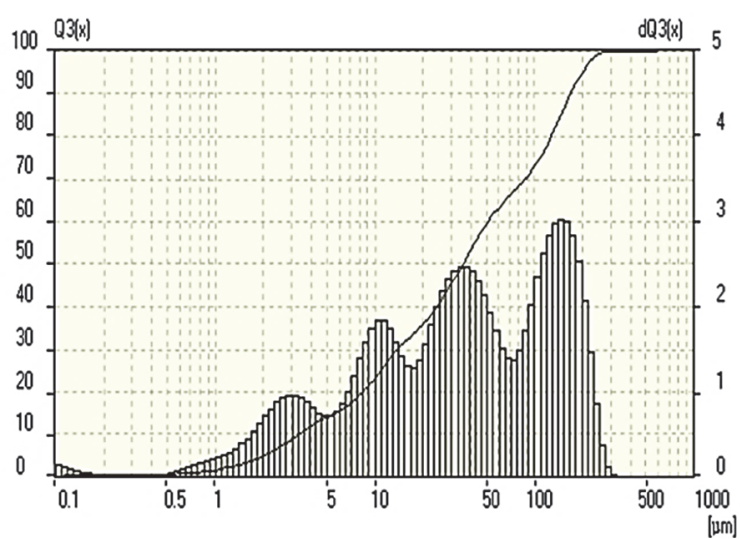

Рис. 6. Дифференциальная и интегральная кривые распределения частиц по размерам порошка, полученного при $\mathrm{pH} 10,60^{\circ} \mathrm{C}$ и выдержке 3 сут

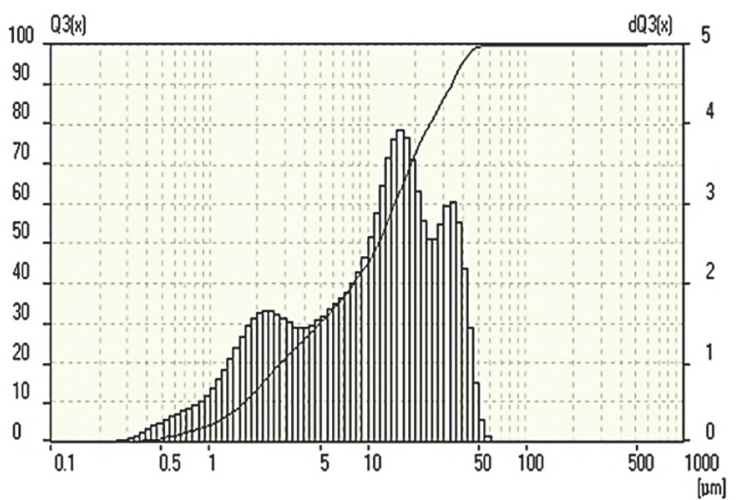

Рис. 7. Дифференциальная и интегральная кривые распределения частиц по размерам порошка, полученного при $\mathrm{pH} 10,60^{\circ} \mathrm{C}$ и обработке маточного раствора электромагнитным излучением СВЧ-диапазона

Для получения образцов керамики на основе синтезированного гидроксиапатита применялся метод 3D-печати. Принципиальная схема разработанного 3D-принтера приведена на рис. 8.

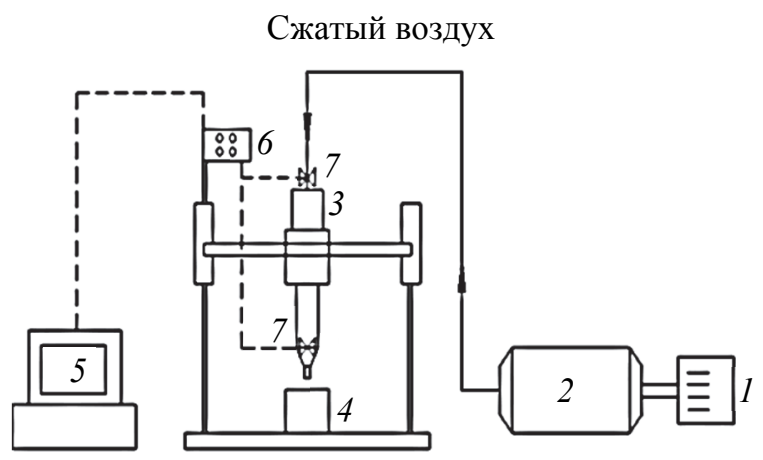

Рис. 8. Принципиальная схема 3D-принтера:

1 - компрессор; 2 - ресивер; 3 - емкость с керамической массой; 4 - образец;

5 - персональный компьютер;

6 - блок управления; 7 - клапан
Керамические массы, используемые для 3Dпечати, должны быть хорошо усреднены, достаточно однородными, с отсутствием воздушных включений, а также характеризоваться заданным дисперсным составом при равномерном распределении связующей добавки в объеме композиции. Отклонение от требуемых параметров может вызвать образование дефектов и разрушение изделия при термической обработке (сушке и обжиге). Материал должен обеспечивать сохранение требуемой формы, т. е. не растекаться во время печати.

Значительное влияние на структурно-реологические свойства керамических масс оказывает влажность и рН. Зависимость динамической вязкости (B-ONE PLUS LR Lamy Rheology, Франция) суспензии гидроксиапатита, полученного при оптимальных условиях синтеза, от влажности и рН приведена на рис. 9 и 10.

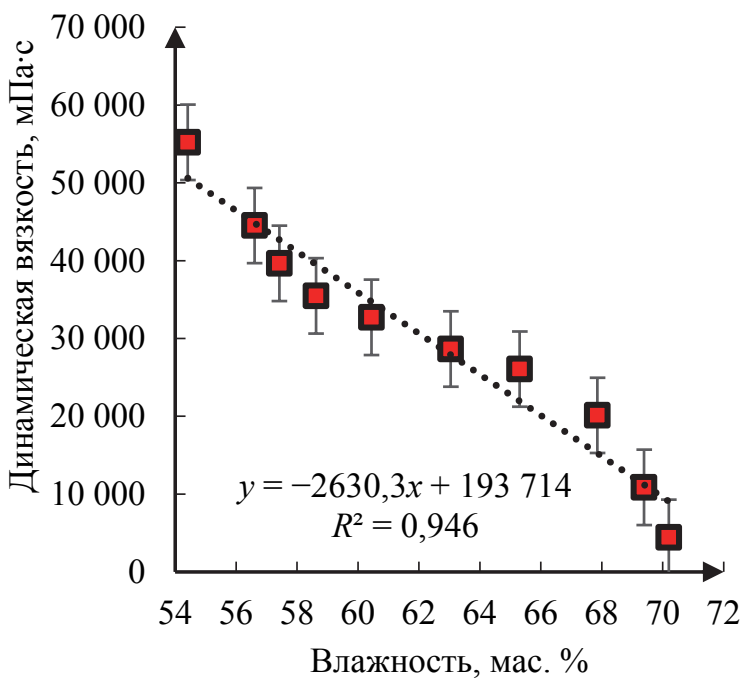

Рис. 9. Зависимость динамической вязкости суспензии гидроксиапатита от влажности (рН 8)

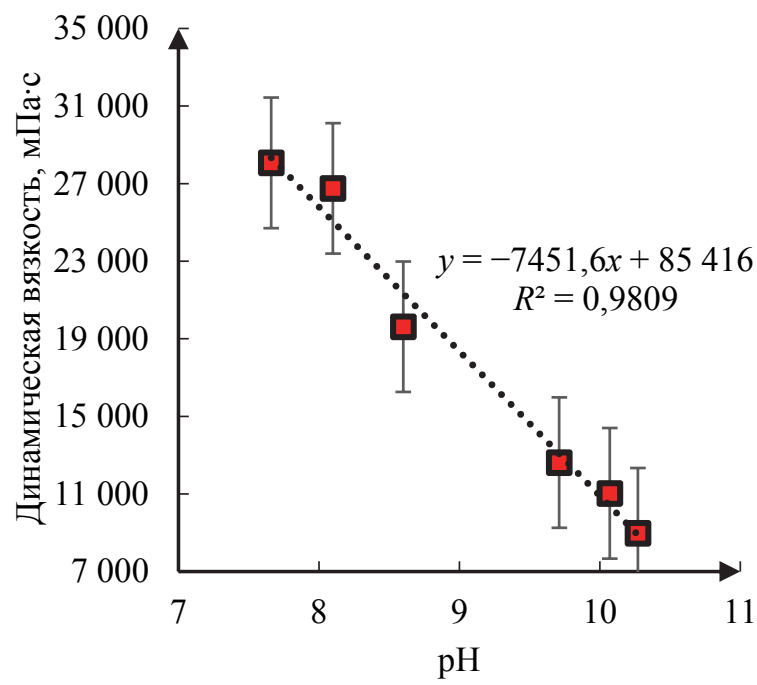

Рис. 10. Зависимость динамической вязкости суспензии гидроксиапатита от рН (влажность 65 мас. \%) 
Из рис. 9 и 10 видно, что повышение влажности суспензии гидроксиапатита, а также $\mathrm{pH}$ приводит к закономерному снижению значений динамической вязкости. При этом для 3D-печати изделий пригодны суспензии с влажностью $57,0-60,0$ мас. \% и $\mathrm{pH} 8$. При влажности более 60 мас. \% и $\mathrm{pH} 8$ керамическая масса растекается при печати.

При использовании в качестве связующих карбоксиметилцеллюлозы (КМЦ) и альгината натрия (пищ., ГОСТ 33310), вводимых в количестве от 0,5 до 2,5 мас. \% сверх $100 \%$ гидроксиапатита, также получены керамические массы, которые по своим реологическим свойствам могут быть использованы для 3D-печати (рис. 11 и 12).

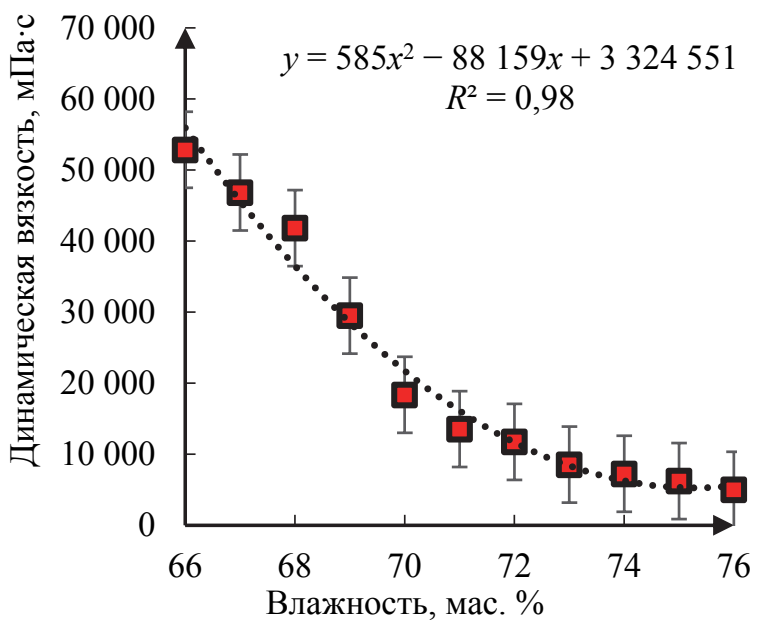

Рис. 11. Зависимость динамической вязкости керамической массы, включающей 1,0 мас. \% КМЦ, от влажности (pH 8)

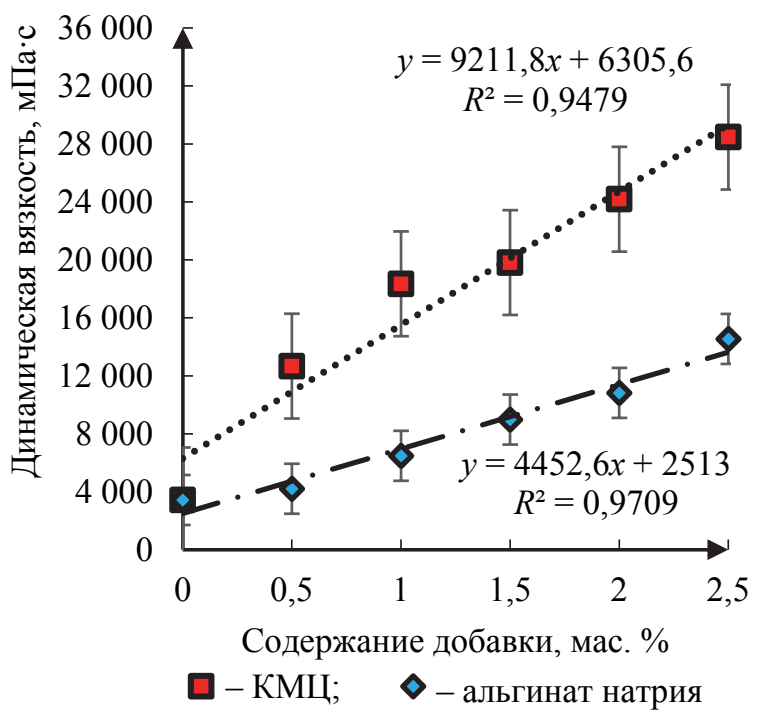

Рис. 12. Зависимость динамической вязкости от содержания добавок (влажность - 70 мас. \%)
Для установления оптимальных температурно-временных режимов обжига изделий использовалась дифференциальная сканирующая калориметрия (ДСК, DSC 404 F3 Pegasus фирмы Netzsch (Германия)).

В соответствии с данными термического анализа гидроксиапатита, синтезированного при оптимальных условиях, имеющиеся на кривой ДСК эндотермические эффекты (рис. 13) можно объяснить протеканием следующих процессов: испарение физически адсорбированной воды, побочных продуктов реакции синтеза $\left(145,6^{\circ} \mathrm{C}\right)$; удаление кристаллизационной воды $\left(452,1^{\circ} \mathrm{C}\right)$; преобразование гексагональной сингонии гидроксиапатита в моноклинную форму и/или стехиометричного гидроксиапатита в оксигидроксиапатит $\left(801,5^{\circ} \mathrm{C}\right)$; разрушение кристаллической структуры гидроксиапатита, плавление $\left(1183,0-1258,1^{\circ} \mathrm{C}\right)$. Экзотермический эффект в области $230-270^{\circ} \mathrm{C}$ связан с одновременным выделением воды и углекислого газа. Вероятно, в данном случае происходит изменение внутренней структуры соединений, сопровождающееся экзотермическим эффектом [34]. Поскольку связующие добавки в состав керамических масс вводят в небольшом количестве - 0,5-2,5 мас. \%, интенсивность эффектов их термического разложения незначительна.

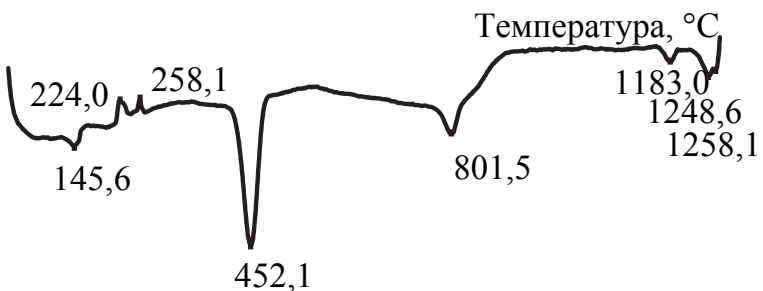

Рис.13. Кривая ДСК гидроксиапатита, синтезированного при оптимальных условиях

Проведенные исследования показали, что изделия необходимо обжигать в температурном интервале $1100-1200^{\circ} \mathrm{C}$, так как при более высоких температурах наблюдается разрушение кристаллической структуры гидроксиапатита.

Сформованные с помощью метода 3D-печати образцы подвергались сушке в сушильном шкафу при температуре $70^{\circ} \mathrm{C}$, а затем обжигу в электрической лабораторной печи SNOL 1,6,2,5.1/13,5-Y1 (Литва) при $1100-1200^{\circ} \mathrm{C}$. Скорость обжига составляла $3^{\circ} \mathrm{C} /$ мин, выдержка при максимальной температуре - 60 мин.

Синтезированная кальцийфосфатная керамика (рис. 14) обладала следующим комплексом технологических и физико-химических свойств: общая усадка - 48,8-64,7\%; кажущаяся плотность - 2030-2980 кг/ $\mathrm{M}^{3}$; водопоглощение (ГОСТ 2409) - 2,2-16,5\%; открытая пористость - 
6,2-32,7\%; механическая прочность при сжатии (ГОСТ 4071.1, испытательная машина Galdabini Quasar 100 (Италия)) - 0,9-3,3 МПа.

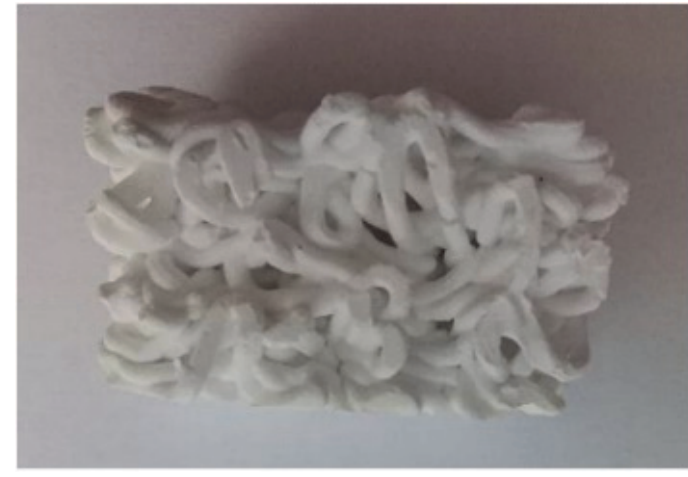

Рис. 14. Внешний вид полученных изделий (длина образца - 20,2 мм)

Рентгенофазовый анализ позволил установить присутствие двух кристаллических фаз в полученных материалах - гидроксиапатит $\mathrm{Ca}_{10}\left(\mathrm{PO}_{4}\right)_{6}(\mathrm{OH})_{2}$ и трикальциевый фосфат $\beta$ $\mathrm{Ca}_{3}\left(\mathrm{PO}_{4}\right)_{2}$. Причем количество $\beta-\mathrm{Ca}_{3}\left(\mathrm{PO}_{4}\right)_{2}$ закономерно увеличивается с повышением температуры обжига, о чем свидетельствует изменение интенсивности дифракционных максимумов (рис. 15).

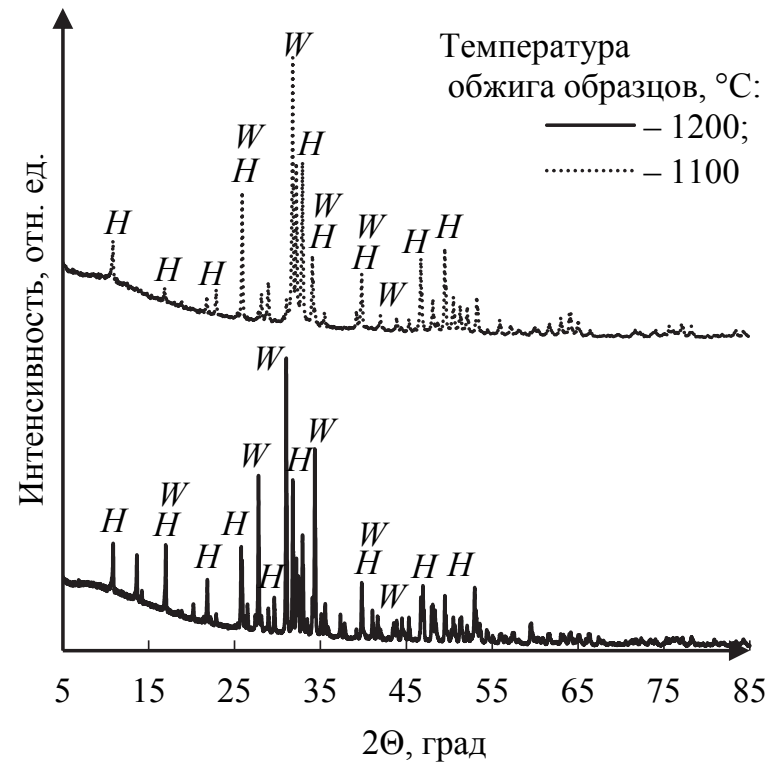

Рис. 15. Дифрактограммы кальцийфосфатной керамики, обожженной при 1100 и $1200^{\circ} \mathrm{C}$ : $H$ - гидроксиапатит $\mathrm{Ca}_{10}\left(\mathrm{PO}_{4}\right)_{6}(\mathrm{OH})_{2}$; $W$ - ортофосфат кальция $\beta-\mathrm{Ca}_{3}\left(\mathrm{PO}_{4}\right)_{2}$

Материал характеризуется присутствием значительного количества пор различной конфигурации, размер которых составляет от 0,5 до 20,0 мкм (рис. 16, 17), кроме того, на поверхности присутствуют микротрещины размером около 100 мкм.
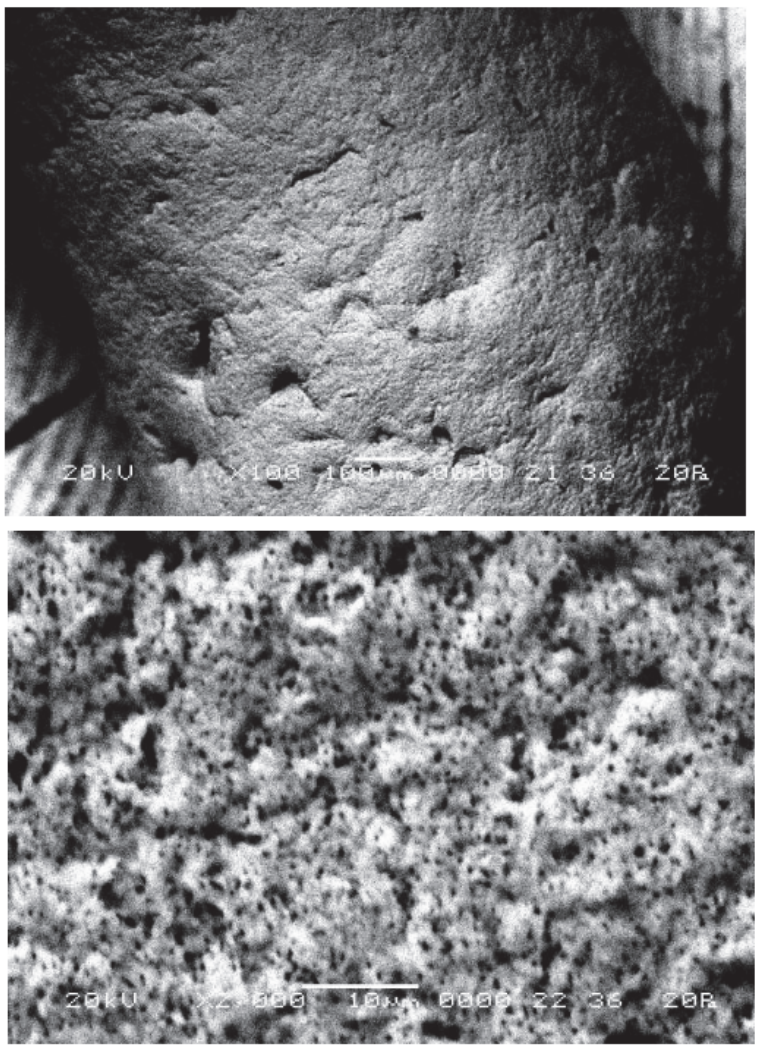

Рис. 16. Микроструктура кальцийфосфатной керамики, полученной с использованием в качестве связки 2,5 мас. \% КМЦ
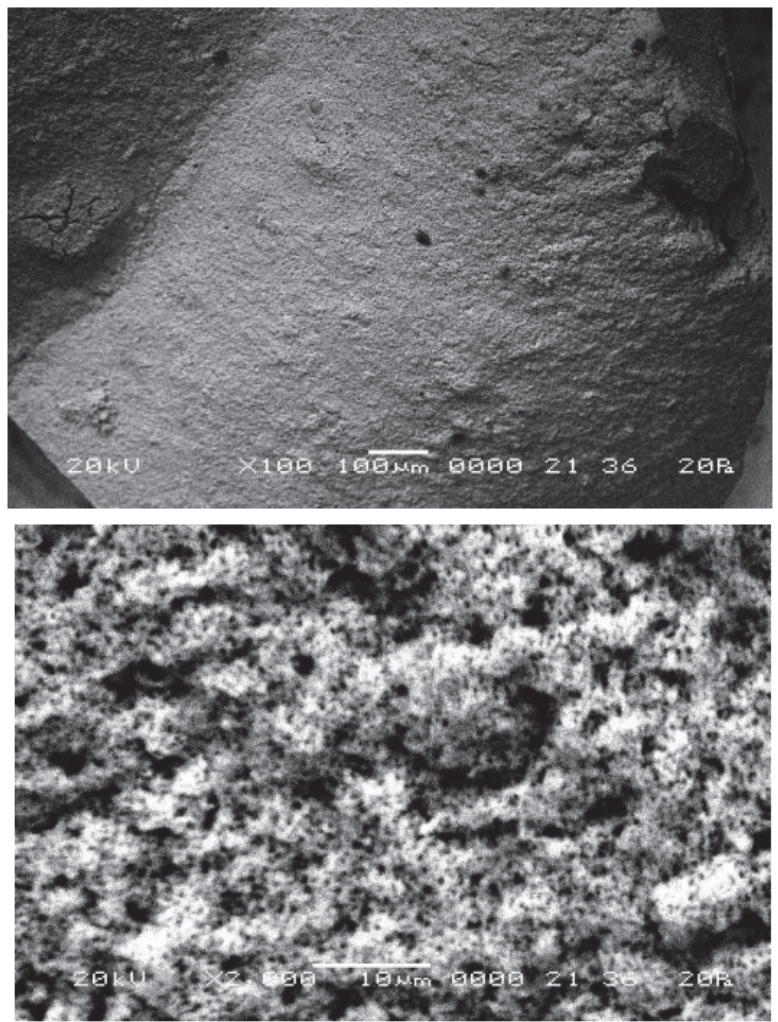

Рис. 17. Микроструктура кальцийфосфатной керамики, синтезированной с использованием 2,5 мас. \% альгината натрия 
В настоящее время проводятся дальнейшие исследования по разработке составов керамических масс, пригодных для 3D-печати, с целью снижения общей усадки, улучшения физико-химических свойств изделий.

Заключение. В настоящей работе проведено комплексное изучение влияния параметров жидкофазного синтеза гидроксиапатита на фазовый и гранулометрический состав полученного порошка, особенности его структуры, что позволило выбрать в качестве оптимальных условий синтеза следующие: $\mathrm{pH} 10$, температура $60^{\circ} \mathrm{C}$, обработка маточного раствора с осадком электромагнитным излучением СВЧ-диапазона мощностью 700 Вт в течение 30 мин.
На основе синтезированного гидроксиапатита разработаны составы кальцийфосфатных керамических масс, которые могут использоваться для 3D-печати изделий. Установлены их технологические свойства: динамическая вязкость - $20000-60000$ мПа с; $\mathrm{pH} 7-8$; влажность - 54-60 мас. \%, а при использовании связующих добавок - 70 мас. \%.

Изучены технологические и физико-химические свойства кальцийфосфатной керамики, полученной методом $3 \mathrm{D}$-печати, во взаимосвязи со структурой и фазовым составом. Определено, что в процессе термообработки при $1100-120^{\circ} \mathrm{C}$ гидроксиапатит частично переходит в ортофосфат кальция $\beta-\mathrm{Ca}_{3}\left(\mathrm{PO}_{4}\right)_{2}$. Микроструктура материала пористая, размер пор составляет 0,5-20,0 мкм.

\section{Список литературы}

1. Баринов С. М., Комлев В. С. Биокерамика на основе фосфатов кальция. М.: Наука, 2005. 204 с.

2. Балакин А. В., Смелов В. Г., Чемпинский Л. А. Применение аддитивных технологий для создания деталей камеры сгорания // Вестник СГАУ. 2012. № 3 (34). С. 47-52.

3. Amirthalingam N., Deivarajan T., Paramasivam M. Mechano chemical synthesis of hydroxyapatite using dolomite // Materials Letters. 2019. Vol. 254. P. 379-382. DOI: 10.1016/j.matlet.2019.07.118.

4. Precipitated calcium phosphatesilicates and their dehydration in air at room temperature / V. A. Sinyaev [et al.] // Russian Journal of Applied Chemistry. 2009. Vol. 82, no 5. P. 789-793. DOI: 10.1134/S1070427209050073.

5. Facile synthesis and characterization of hydroxyapatite particles for high value nanocomposites and biomaterials / F. Miculescu [et al.] // Vacuum. 2017. Vol. 146. P. 614-622. DOI: 10.1016/j.vacuum.2017.06.008.

6. Bogdanova E. A., Sabirzyanov N. A. Synthesis and study of nanosized biomaterials based on hydroxyapatite // Nanosystems: physics, chemistry, mathematics. 2014. No. 5 (4). P. 590-596.

7. Longinova N. M., Kozyreva N. A., Lipochkin S. V. Physocochemical properties of hydroxylapatite produced by precipitation // Glass and Ceramics. 2000. Vol. 57, issue 5-6. P. 172-173. DOI: 10.1007/BF02681268.

8. Study of synthetic hydroxyapatite by the method of high-resolution transmission electron microscopy: morphology and growth direction / E. I. Suvorova [et al.] // Crystallography Reports. 2000. Vol. 45, issue 5. P. 857-861. DOI: 10.1134/1.1312936.

9. О выборе архитектуры остеокондуктивных биокерамических имплантатов / А. А. Тихонов [и др.] // Материаловедение. 2018. № 8. C. 43-48. DOI: 10.31044/1684-579X-2018-0-8-43-48.

10. Thermal decomposition of hydroxyapatite in air atmosphere / Ch.-J. Liao [et al.] // Ceramic International. 1999. Vol. 20. P. 1807-1813. DOI: 10.1016/s0142-9612(99)00076-9.

11. Керамические материалы на основе гидроксиапатита, синтезированного из растворов различной концентрации исходных реагентов / Т. В. Сафронова [и др.] // Неорганические материалы. 2007. № 8. C. 1005-1014.

12. Vlasov A. S., Ludanova A. S. Effect of the parameters of synthesis on the properties of hydroxyapatite // Glass and Ceramics. 1994. Vol. 51, issue 7-8. P. 261-262. DOI: 10.1007/BF00680662.

13. Куляшова К. С., Шаркеев Ю. П. Получение синтетического гидроксиапатита для формирования биопокрытий на имплантатах медицинского назначения // Химия в интересах устойчивого развития. 2011. № 19. С. 447-453.

14. Получение нанокристаллического гидроксиапатита методом химического осаждения с использованием биогенного источника кальция / Д. Л. Голощапов [и др.] // Конденсированные среды и межфазные границы. 2011. Т. 13, № 4. С. 427-441.

15. Jyotsna P., Vijayakumar P. Synthesis and characterization of hydroxyapatite nanoparticles and their cytotoxic effect on a fish vertebra derived cell line // Biocatalysis and Agricultural Biotechnology. 2020. Vol. 25. DOI: 10.1016/j.bcab.2020.101612.

16. Dorozhkin S. V. A novel environmentally friendly process for the fabrication of calcium phosphate bioceramics // Inorganic Materials. 2008. Vol. 44, issue 2. P. 207-210. DOI: 10.1134/S0020168508020234.

17. Komlevel V. S., Barinov S. M. Porous hydroxyapatite ceramics of bimodal poresize distribution // J. of M. Scientists. 2002. Vol. 13. P. 295-299. DOI: 10.1023/a:1014015002331.

18. Керамика на основе порошка фосфата кальция, синтезированного из сахарата кальция и гидрофосфата аммония / Т. В. Сафронова [и др.] // Материаловедение. 2016. № 3. С. 43-48. 
19. Двухфазная керамика в системе $\mathrm{CaO}-\mathrm{P}_{2} \mathrm{O}_{5}$ на основе порошка, синтезированного из ацетата кальция и гидрофосфата аммония / Т. В. Сафронова [и др.] // Стекло и керамика. 2013. № 2. С. 44-31.

20. Синтез порошка фосфата кальция из лактата кальция и гидрофосфата аммония для получения биокерамики / Т. В. Сафронова [и др.] // Неорганические материалы. 2017. Т. 53, № 8. С. 859-868.

21. Synthesis and physicochemical characterization of carboxymethylcellulose-containing calcium hydroxylapatite / Zh. A. Ezhova [et al.] // Russian Journal of Inorganic Chemistry. 2006. Vol. 51, issue 2. P. 332-336. DOI: 10.1134/S0036023606020239.

22. Facile syntheses of three-dimensional porous hydroxyapatite using carboxymethylcellulose as a template / G. Qian [et al.] // Results in Physics. 2017. No. 7. P. 1623-1627. DOI: 10.1016/j.rinp.2017.04.033.

23. Chena R., Shen J. The synthesis of hydroxyapatite crystals with various morphologies via the solvothermal method using double surfactants // Materials Letters. 2020. Vol. 259. DOI: 10.1016/j.matlet.2019.126881.

24. Получение наноструктур гидроксиапатита, обладающих высокой удельной поверхностью Е. Ю. Каракатенко [и др.] // Успехи в химии и химической технологии. 2017. Т. 31, № 13. С. 34-36.

25. Фадеева Е. Ю., Леткин Е. А., Королёва М. Ю. Синтез наночастиц гидроксиапатита, стабилизированных Вrij 30 // Успехи в химии и химической технологии. 2016. Т. 30, № 12. С. 46-48.

26. Получение порошка гидроксиапатита в ходе жидкофазного синтеза / Т. И. Гузеева [и др.] // Известия Томского политехнического университета. 2009. Т. 315, № 3. С. 47-50.

27. Hench L. L. Bioceramics // Journal of the American Ceramic Society. 1998. Vol. 81, issue 7. P. 1705-1728. DOI: 10.1111/j.1151-2916.1998.tb02540.x.

28. Yeong K. C. B., Wang J., Ng S. C. Mechanochemical synthesis of nanocrystalhydroxyapatite from CaO and $\mathrm{CaHPO}_{4} / /$ Biomaterials. 2001. Vol. 22, no. 20. P. 2705-2712. DOI: 10.1016/s0142-9612(00)00257-x.

29. Ultrasonic synthesis of hydroxyapatite in non-cavitation and cavitation modes / A. L. Nikolaev [et al.] // Ultrasonics - Sonochemistry. 2018. Vol. 44. P. 390-397. DOI: 10.1016/j.ultsonch.2018.02.047.

30 . Chen J. Regulatory synthesis and characterization of hydroxyapatite nanocrystals by a microwaveassisted hydrothermal method // Ceramics International. 2020. Vol. 46, issue 2. P. 2185-2193. DOI: 10.1016/j.ceramint.2019.09.203.

31. Физико-химические характеристики ископаемых костных остатков млекопитающих и проблема оценки их относительного возраста. В 2 ч. Часть 2: ИК- и радиоспектроскопия, микроскопия / С. Л. Вотяков [и др.]. Екатеринбург: Гощицкий, 2009. 82 с.

32. Солоненко А. П. Синтез смесей гидроксиапатита и аморфного силиката кальция // Современные научные исследования и инновации. 2015. № 10 (54). С. 35-40.

33. Применение колебательной спектроскопии для экспресс-анализа композитных материалов на основе акриловых гидрогелей и гидроксиапатита / И. Е. Болдескул [и др.] // Методы и объекты химического анализа. 2009. Т. 4, № 1. С. 92-96.

34. Characterization and annealing performance of calcium phosphate nanoparticles synthesized co-precipitation method / M. A. Ahmed [et al.] // Ceramics International. 2014. Vol. 40, issue 8. P. 12807-12820. DOI: $10.1016 /$ j.ceramint.2014.04.135.

\section{References}

1. Barinov S. M., Komlev V. S. Biokeramika na osnove fosfatov kal'tsiya [Calcium phosphate based bioceramics]. Moscow, Nauka Publ., 2005. 204 p.

2. Balakin A. V., Smelov V. G., Chempinskiy L. A. Additive technology application details of combustion. Vestnik SGAU [Bulletin of Samara University], 2012, no. 3 (34), pp. 47-52 (In Russian).

3. Amirthalingam N., Deivarajan T., Paramasivam M. Mechano chemical synthesis of hydroxyapatite using dolomite. Materials Letters, 2019, vol. 254, pp. 379-382. DOI: 10.1016/j.matlet.2019.07.118.

4. Sinyaev V. A., Levchenko L. V., Shustikova E. S., Karzhaubaeva R. A., Gaysina G. D. Precipitated calcium phosphatesilicates and their dehydration in air at room temperature. Russian Journal of Applied Chemistry, 2009, vol. 82, no. 5, pp. 789-793. DOI: 10.1134/S1070427209050073.

5. Miculescu F., Mocanu A.-C., Dascălu C. A., Maidaniuc A., Batalu D., Berbecaru A., Voicu S. I., Miculescu M., Thakur V. K., Ciocan L. T. Facile synthesis and characterization of hydroxyapatite particles for high value nanocomposites and biomaterials. Vacuum, 2017, vol. 146, pp. 614-622. DOI: 10.1016/j.vacuum.2017.06.008.

6. Bogdanova E. A., Sabirzyanov N. A. Synthesis and study of nanosized biomaterials based on hydroxyapatite. Nanosystems: physics, chemistry, mathematics, 2014, no. 5 (4), pp. 590-596.

7. Longinova N. M., Kozyreva N. A., Lipochkin S. V. Physocochemical properties of hydroxylapatite produced by precipitation. Glass and Ceramics, 2000, vol. 57, issue 5-6, pp. 172-173. DOI: 10.1007/BF02681268.

8. Suvorova E. I., Polyak L. E., Komarov V. F., Melikhov I. V. Study of synthetic hydroxyapatite by the method of high-resolution transmission electron microscopy: morphology and growth direction. Crystallography Reports, 2000, vol. 45, issue 5, pp. 857-861. DOI: 10.1134/1.1312936. 
9. Tikhonov A. A., Yevdokimov P. V., Putlyayev V. I., Safronova T. V., Filippov Ya. Yu. On architecture of osteoconductive bioceramic implants. Material Science, 2018, no. 8, pp. 43-48. DOI: 10.31044/1684579X-2018-0-8-43-48.

10. Liao Ch.-J., Lin F.-H., Chen K.-Sh., Sun J.-Sh. Thermal decomposition of hydroxyapatite in air atmosphere. Ceramic International, 1999, vol. 20, pp. 1807-1813. DOI: 10.1016/s0142-9612(99)00076-9.

11. Safronova T. V., Shekhirev M. A., Putlyaev V. I., Tret'yakov Yu. D. Hydroxyapatite-based ceramic materials prepared using solutions of different concentrations. Neorganicheskiye materialy [Inorganic Materials], 2007, no. 8, pp. 1005-1014 (In Russian).

12. Vlasov A. S., Ludanova A. S. Effect of the parameters of synthesis on the properties of hydroxyapatite. Glass and Ceramics, 1994, vol. 51, issue 7-8, pp. 261-262. DOI: 10.1007/BF00680662.

13. Kulyashova K. S., Sharkeev Yu. P. Obtaining synthetic hydroxyapatite for the formation of biocoatings on implants for medical purposes. Khimiya vinteresakh ustoychivogo razvitiya [Chemistry for Sustainable Development], 2011, no. 19, pp. 447-453 (In Russian).

14. Goloshchapov D. L., Kashkarov V. M., Rumyantseva N. A., Seredin P. V., Len'shin A. S., Agapov B. L., Domashevskaya E. P. Synthesis of nanocrystalline hydroxyapatite by the precipitation process using natural source. Kondensirovannyye sredy i mezhfaznyye granitsy [Condensed matter and interphases], 2011, vol. 13, no. 4, p. 427-441 (In Russian).

15. Jyotsna P., Vijayakumar P. Synthesis and characterization of hydroxyapatite nanoparticles and their cytotoxic effect on a fish vertebra derived cell line. Biocatalysis and Agricultural Biotechnology, 2020, vol. 25. DOI: 10.1016/j.bcab.2020.101612.

16. Dorozhkin S. V. A Novel environmentally friendly process for the fabrication of calcium phosphate bioceramics. Inorganic Materials, 2008, vol. 44, issue 2, pp. 207-210. DOI: 10.1134/S0020168508020234.

17. Komlevel V. S., Barinov S. M. Porous hydroxyapatite ceramics of bimodal poresize distribution. J. of M. Scientists, 2002., vol. 13, pp. 295-299. DOI: 10.1023/a:1014015002331.

18. Safronova T. V., Kazakova G. K., Evdokimov P. V., Shatalova T. B., Knot'ko A. V., Korotkova A. V., Putlyaev V. I. Ceramics based on calcium phosphate powder synthesized from calcium saccharate and ammonium hydrogen phosphate. Materialovedeniye [Materials Science], 2016, no. 3, pp. 43-48 (In Russian).

19. Safronova T. V., Putlyaev V. I., Kazakova G. K., Korneichuk S. A. Biphase CaO- $\mathrm{P}_{2} \mathrm{O}_{5}$ ceramic based on powder synthesized from calcium acetate and ammonium hydrophosphate. Steklo $i$ keramika [Glass and ceramics], 2013, no. 2, pp. 44-31 (In Russian).

20. Safronova T. V., Putlyaev V. I., Andreev M. D., Filippov Ya. Yu., Knot'ko A. V., Shatalova T. B., Evdokimov P. V. Synthesis of calcium phosphate powder from calcium lactate and ammonium hydrogen phosphate for the fabrication of bioceramics. Neorganicheskiye materialy [Inorganic Materials], 2017, vol. 53, no. 8, pp. 859-868 (In Russian).

21. Ezhova Zh. A., Koval' E. M., Zakharov N. A., Kalinnikov V. T. Synthesis and physicochemical characterization of carboxymethylcellulose-containing calcium hydroxylapatite. Russian Journal of Inorganic Chemistry, 2006, vol. 51, issue 2, pp. 332-336. DOI: 10.1134/S0036023606020239.

22. Qian G., Liu W., Zheng L., Liu L. Facile syntheses of three-dimensional porous hydroxyapatite using carboxymethylcellulose as a template. Results in Physics, 2017, no. 7, pp. 1623-1627. DOI: 10.1016/ j.rinp.2017.04.033.

23. Chena R., Shen J. The synthesis of hydroxyapatite crystals with various morphologies via the solvothermal method using double surfactants. Materials Letters, 2020, vol. 259. DOI: 10.1016/j.matlet.2019.126881.

24. Karakatenko E. Yu., Khayrullin A. I., Ivanov P. I., Koroleva M. Yu. Synthesys hydroxyapatite nanostructures with high surface area. Uspekhi v khimii i khimicheskoy tekhnologii [Advances in chemistry and chemical technology], 2017, vol. 31, no. 13, pp. 34-36 (In Russian).

25. Fadeeva E. Yu., Letkin E. A., Koroleva M. Yu. Synthesis of hydroxyapatite nanoparticles stabilized by Brij 30. Uspekhi v khimii i khimicheskoy tekhnologii [Advances in chemistry and chemical technology], 2016, vol. 30, no. 12, pp. 46-48 (In Russian).

26. Guzeeva T. I., Guzeev V. V., Leonova L. A., Lelyuk O. A., Krikunenko A. S., Shatokhina Yu. V. Obtaining hydroxyapatite powder at liquid-phase synthesis. Izvestiya Tomskogo politekhnicheskogo universiteta [Bulletin of the Tomsk Polytechnic University], 2009, vol. 315, no. 3, pp. 47-50 (In Russian).

27. Hench L. L. Bioceramics. Journal of the American Ceramic Society, 1998, vol. 81, issue 7, pp. 17051728. DOI: 10.1111/j.1151-2916.1998.tb02540.x.

28. Yeong K. C. B., Wang J., Ng S. C. Mechanochemical synthesis of nanocrystalhydroxyapatite from $\mathrm{CaO}$ and $\mathrm{CaHPO}_{4}$. Biomaterials, 2001, vol. 22, no. 20, pp. 2705-2712. DOI: 10.1016/s0142-9612(00)00257-x.

29. Nikolaev A. L., Gopin A. V., Severin A. V., Rudin V. N., Mironov M. A., Dezhkunov N. V. Ultrasonic synthesis of hydroxyapatite in non-cavitation and cavitation modes. Ultrasonics - Sonochemistry, 2018, vol. 44, pp. 390-397. DOI: 10.1016/j.ultsonch.2018.02.047. 
30. Chen J. Regulatory synthesis and characterization of hydroxyapatite nanocrystals by a microwaveassisted hydrothermal method. Ceramics International, 2020, vol. 46, issue 2, pp. 2185-2193. DOI: 10.1016/j.ceramint.2019.09.203.

31. Votyakov S. L., Kiseleva D. V., Sadykova N. O., Smirnov N. G., Shchapova Yu. V. Fiziko-khimicheskiye kharakteristiki iskopayemykh kostnykh ostatkov mlekopitayushchikh i problema otsenki ikh otnositel'nogo vozrasta. V 2 chastyakh. Chast' 2: IK-i radiospektroskopiya, mikroskopiya [Physicochemical characteristics of fossilized mammal bone remains and the problem of their relative age. In 2 parts. Part 2: IRand radiospectroscopy, microscopy]. Yekaterinburg, Goshchitskiy Publ., 2009. 82 p.

32. Solonenko A. P. Synthesis of hydroxyapatite and amorphous calcium silicate mixtures. Sovremennyye nauchnyye issledovaniya i innovatsii [Modern scientific researches and innovations], 2015, no. 10 (54), pp. 35-40 (In Russian).

33. Boldeskul I. E., Samchenko Yu. M., Sukhodub L. B., Ul’berg Z. R., Sukhodub L. F., Bereza L. I. Application of vibrational spectroscopy in express analysis of acrylic hydrogel and hydroxyapatite based composite materials. Metody i ob 'yekty khimicheskogo analiza [Methods and objects of chemical analysis], 2009, vol. 4, no. 1, pp. 92-96 (In Russian).

34. Ahmed M. A., Mansour S. F., El-dek S. I., Abd-Elwahab S. M., Ahmed M. K. Characterization and annealing performance of calcium phosphate nanoparticles synthesized co-precipitation method. Ceramics International, 2014, vol. 40, issue 8, pp. 12807-12820. DOI: 10.1016/j.ceramint.2014.04.135.

\section{Информация об авторах}

Шиманская Анна Николаевна - кандидат технических наук, ассистент кафедры технологии стекла и керамики. Белорусский государственный технологический университет $(220006$, г. Минск, ул. Свердлова, 13a, Республика Беларусь). E-mail: shimanskaya@belstu.by

Попов Ростислав Юрьевич - кандидат технических наук, доцент кафедры технологии стекла и керамики. Белорусский государственный технологический университет (220006, г. Минск, ул. Свердлова, 13a, Республика Беларусь). E-mail: rospopov@mail.ru

Пантелеенко Федор Иванович - доктор технических наук, профессор кафедры порошковой металлургии, сварки и технологии материалов, член-корреспондент НАН Беларуси, заслуженный деятель науки Республики Беларусь. Белорусский национальный технический университет (220013, г. Минск, ул. Я. Коласа, 24, корп. 7, Республика Беларусь). E-mail: panteleenkofi@mail.ru

Подсосонная Александра Дмитриевна - магистрант кафедры технологии стекла и керамики. Белорусский государственный технологический университет (220006, г. Минск, ул. Свердлова, 13a, Республика Беларусь). E-mail: pod.sosna@inbox.ru

Байгазин Дмитрий Александрович - студент. Белорусский государственный технологический университет (220006, г. Минск, ул. Свердлова, 13а, Республика Беларусь). E-mail: baigazin.dima@mail.ru

Поспелов Андрей Владимирович - младший научный сотрудник Центра физико-химических методов исследования. Белорусский государственный технологический университет (220006, г. Минск, ул. Свердлова, 13а, Республика Беларусь). E-mail: Andrei29088@mail.ru

\section{Information about the authors}

Shymanskaya Hanna Mikalaeuna - PhD (Engineering), Assistant Lecturer, the Department of Glass and Ceramics Technology. Belarusian State Technological University (13a, Sverdlova str., 220006, Minsk, Republic of Belarus). E-mail: shimanskaya@belstu.by

Popov Rostislav Yur'evich - PhD (Engineering), Assistant Professor, the Department of Glass and Ceramics Technology. Belarusian State Technological University (13a, Sverdlova str., 220006, Minsk, Republic of Belarus). E-mail: rospopov@mail.ru

Pantsialeyenka Fedor Ivanovich - DSc (Engineering), Professor, the Department of Powder Metallurgy, Welding and Materials Technology, NAS Corresponding Member, Honoured Scientist of the Republic of Belarus. Belarusian National Technical University (24, build. 7, Ya. Kolasa str., 220013, Minsk, Republic of Belarus). E-mail: panteleenkofi@mail.ru

Podsosonnaya Alexandra Dmitrievna - Master's degree student, the Department of Glass and Ceramics Technology. Belarusian State Technological University (13a, Sverdlova str., 220006, Minsk, Republic of Belarus). E-mail: pod.sosna@inbox.ru

Baihazin Dzmitry Alyaksandravich - student. Belarusian State Technological University (13a, Sverdlova str., 220006, Minsk, Republic of Belarus).E-mail: baigazin.dima@mail.ru

Pospelov Andrey Vladimirovich - Junior Researcher, the Center for Physical and Chemical Research Methods. Belarusian State Technological University (13a, Sverdlova str., 220006, Minsk, Republic of Belarus).E-mail: Andrei29088@mail.ru 